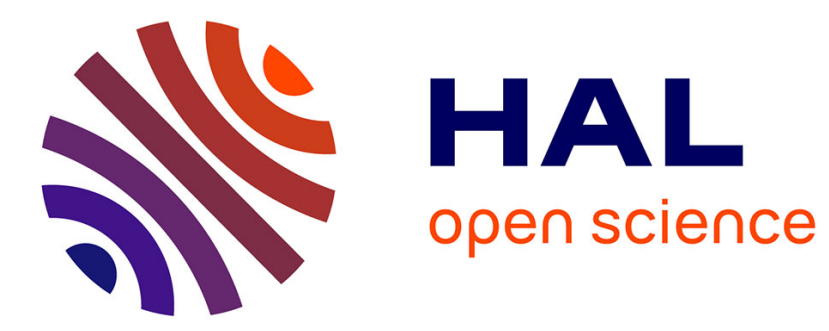

\title{
Forms of Mathematization (14th-17th Centuries)
}

Sophie Roux

\section{To cite this version:}

Sophie Roux. Forms of Mathematization (14th-17th Centuries). Early Science and Medicine, 2010, 15, pp.319-337. halshs-00806470

\section{HAL Id: halshs-00806470 \\ https://shs.hal.science/halshs-00806470}

Submitted on 2 Apr 2013

HAL is a multi-disciplinary open access archive for the deposit and dissemination of scientific research documents, whether they are published or not. The documents may come from teaching and research institutions in France or abroad, or from public or private research centers.
L'archive ouverte pluridisciplinaire HAL, est destinée au dépôt et à la diffusion de documents scientifiques de niveau recherche, publiés ou non, émanant des établissements d'enseignement et de recherche français ou étrangers, des laboratoires publics ou privés. 


\title{
Forms of mathematization $\diamond$
}

\author{
Sophie Roux \\ (université de Grenoble / Institut universitaire de France)*
}

According to a grand narrative that long ago ceased to be told, there was a seventeenth century Scientific Revolution, during which a few heroes conquered nature thanks to mathematics. ${ }^{1}$ This grand narrative began with the exhibition of quantitative laws that these heroes, Galileo and Newton for example, had disclosed: the law of falling bodies, according to which the speed of a falling body is proportional to the square of the time that has elapsed since the beginning of its fall; the law of gravitation, according to which two bodies are attracted to one another in proportion to the sum of their masses and in inverse proportion to the square of the distance separating them - according to his own preferences, each narrator added one or two quantitative laws of this kind. The essential feature was not so much the

$\diamond$ Except for one, the essays presented in this special issue were originally delivered as talks during the seminar La mathématisation comme problème that was organized at the university of Grenoble between January 2007 and June 2008 on a monthly basis, and thereafter discussed during an editorial meeting that took place in Lyon in January 2009. Cluster 14 of the Région Rhône-Alpes provided the financial help that these academic events required. Edith Sylla generously agreed to contribute to this special issue without having participated to the seminar, and I thank her for that. I wish also to thank all participants to the seminar for the lively and sometimes heated discussions we had, the editor of Early Science and Medicine for his willingness to consider the essays for a special issue, some anonymous referees for their sharp comments and, finally, Jürgen Renn for having invited me to the Max Planck Institut für Wissenschaftsgeschichte throughout the period when this special issue was being completed. During my stay at the MPIWG, I met Fokko Jan Dijksterhuis, who is currently working on a similar project, The Uses of Mathematics in the Dutch Republic: I regret that we did not meet earlier. grenoble.fr

* PLC, BP 47, 1281 avenue Centrale 38040, Grenoble Cedex 9, France. Sophie.Roux@upmf-

Edmund Husserl and Alexandre Koyré are the two key-figures in the emergence of the grand narrative of mathematization of nature. Husserl claimed that Galileo was the first to mathematize nature, i.e., according to Husserl, to surreptitiously substitute mathematical idealities for the concrete things of the intuitively given surrounding world (The crisis of European sciences and transcendental phenomenology. An introduction to phenemenological philosophy, Engl. tr. David Carr (Evanston, 1970), § 9, 23-59). Koyré introduced Husserlianism in the history of science and argued that the mathematization (idealization) of nature triggered the Scientific Revolution from Galileo to Newton. For a first presentation of Koyré's theses, see Gérard Jorland, $L a$ science dans la philosophie. Les recherches épistémologiques d'Alexandre Koyré (Paris, 1981); on the influence that $\S 9$ of the Crisis may have had on Koyré, see François De Gandt, Husserl et Galilée. Sur la crise des sciences européennes (Paris, 2005), 97-103. Mathematization of nature is assumed to epitomize the Scientific Revolution in the very titles of the following classical studies, whether or not they endorse idealism: William Shea (ed.), Nature Mathematized. Historical and Philosophical Case Studies in Classical Modern Natural Philosophy (Dordrecht, 1983); Joella G. Yoder, Unrolling time : Christiaan Huygens and the Mathematization of Nature (Cambridge, 1988); Lino Conti, La matematizzazione dell'universo : momenti della cultura matematica tra '500 e '600 (S. Maria degli Angeli, 1992); Michel Blay, "La mathématisation de la nature," in L'Europe des sciences. Constitution d'un espace scientifique, ed. Michel Blay and Efthymios Nicolaïdis (Paris, 2001), 115-134, passim. In the following footnotes, I shall give a few non-historical references, in order to make clear that idealism is not the only relevant philosophical tradition. 
examples that were chosen, but, rather, the more or less explicit theses that accompanied them. First, mathematization would be taken as the criterion for distinguishing between a qualitative Aristotelian philosophy and the new quantitative physics. Secondly, mathematization was founded on the metaphysical conviction that the world was created pondere, numero et mensura, or that the ultimate components of natural things are triangles, circles, and other geometrical objects. This metaphysical conviction had two immediate consequences: that all the phenomena of nature can be in principle submitted to mathematics and that mathematical language is transparent; it is the language of nature itself and has simply to be picked up at the surface of phenomena. Finally, it goes without saying that, from a social point of view, the evolution of the sciences was apprehended through what has been aptly called the "relay runner model," according to which science progresses as a result of individual discoveries. $^{2}$

Grand narratives such as this are perhaps simply fictions doomed to ruin as soon as they are clearly expressed. In any case, the very assumption on which this grand narrative relies can be brought into question: even in the canonical domain of mechanics, the relevant epistemological units crucial to understanding the dynamics of the Scientific Revolution are perhaps not a few laws of motion, but a complex set of problems embodied in mundane objects. ${ }^{3}$ Moreover, each of the theses just mentioned was actually challenged during the long period of historiographical reappraisal, out of which we have probably not yet stepped.

Against the sharp distinction between a qualitative Aristotelian philosophy and the new quantitative physics, numerous studies insist that Rome wasn't built in a day, so to speak. Since Antiquity, there have always been mixed sciences; the emergence of pre-classical mechanics depends on both medieval treatises and the practical challenges met by Renaissance engineers. It is indeed true that, for Aristotle, mathematics merely captures the superficial properties of things, but the Aristotelianisms were many during the Renaissance and the Early Modern period, with some of them being compatible with the introduction of mathematics in natural philosophy. ${ }^{4}$ In addition, the gap between the alleged program of

\footnotetext{
2 Jochen Büttner, Peter Damerow, Jürgen Renn, “Galileo's Unpublished Treatises. A Case Study on the Role of Shared Knowledge in the Emergence and Dissemination of an Early Modern 'New Science'," in The Reception of the Galilean Science of Motion in Seventeenth-Century Europe, ed. Carla Rita Palmerino and J.M.M.H. Thijssen (Dordrecht, 2004), 99-117, here 100.

$3 \quad$ Alan Gabbey, "The Case of Mechanics: One Revolution or Many?" in Reappraisals of the Scientific Revolution, ed. David C. Lindberg and Robert S. Westman (Cambridge, 1990), 493-528; Domenico Bertoloni Meli, Thinking with Objects. The Transformation of Mechanics in the Seventeenth Century (Baltimore, 2006), 16, passim.

4 Peter Damerow, Gideon Freudenthal, Peter McLaughlin and Jürgen Renn, Exploring the Limits of Preclassical Mechanics, $2^{\text {nd }}$ edition (New York, 2004); Walter R. Laird and Sophie Roux (ed.), Mechanics and Natural Philosophy before the Scientific Revolution (Dordrecht, 2008).
} 
mathematizing nature and its effective realization was underlined as most natural phenomena actually escaped mathematization; at best they were enrolled in what Thomas Kuhn began to rehabilitate under the appellation of the "Baconian sciences," i.e., empirical investigations aiming at establishing isolated facts, without relating them to any overarching theory. ${ }^{5}$ Hence, mathematization of nature cannot pretend to capture a historical fact: at most, it expresses an indeterminate task for generations to come.

On top of these first two considerations, and against the thesis of the neutrality of the mathematical language, it was urged that mathematics is not "only a language" and that, exactly as other symbolic means or cognitive tools, it has its own constraints. ${ }^{6}$ For example, it has been thoroughly explained that the Euclidean theory of proportions both guides and frustrates the Galilean analysis of motion; its shortages were particularly clear with respect to the expression of continuity, which is crucial in the case of motion. ${ }^{7}$ Consequently, when calculus was invented and applied to the analysis of motion, it was not a transposition that left things as they stood. Even more clearly than in the case of a translation from one natural language to another, the shift from one symbolic language to another entails that certain possibilities are opened while others are closed. ${ }^{8}$ The cognitive constraints imposed by established mathematical theories, as seen in the theory of proportions or calculus, were not the only ones to be studied in relation to mathematization. Certain schemes dependent on the grammar of natural languages, e.g., the scheme of contrariety, or certain symbolic means of representation, e.g. geometrical diagrams and numerical tables, were also subject to such scrutiny. $^{9}$

Lastly, it was insisted that, even if we concede the existence of scientific geniuses, mathematics is largely produced by intellectual communities and embedded within social practices. More attention was consequently paid to the forms of communication in given mathematical networks, or to the teaching of the discipline in, for example, Jesuit colleges

\footnotetext{
5 Thomas S. Kuhn, "Mathematical versus Experimental Tradition in the Development of Physical Science," in The Essential Tension (Chicago, 1977), 31-65, here 41-51.

$6 \quad$ Gaston Bachelard, L'activité rationaliste de la physique contemporaine (Paris, 1951), 28-29; GillesGaston Granger, Essai d'une philosophie du style (Paris, 1969), 21-24.

Enrico Giusti, "Il filosofo geometra. Matematica e filosofia naturale in Galileo," Nuncius, 9 (1994), 485-498; id., "Galileo e le leggi del moto," in Galileo Galilei, Discorsi e dimostrazioni matematiche intorno a due nuove scienze, ed. E. Giusti (Turin, 1990).

$8 \quad$ Michel Blay, La naissance de la mécanique analytique : la science du mouvement au tournant des XVII ${ }^{e}$ et XVIII siècles (Paris, 1992); id., Les raisons de l'infini: Du monde clos à l'univers mathématique (Paris, 1993), Engl. tr. by M. B. DeBevoise, Reasoning with the Infinite. From the Closed World to the Mathematical Universe (Chicago, 1998).

Peter Damerow and al., Exploring the Limits, 71-134. For diagrams, see, moreover, the references given below, footnotes 25 and 26; for numerical tables, see Meli, Thinking with Objects, p. 109-112, p. 131-133, 179-181, 226-227; id., "The Role of Numerical Tables in Galileo and Mersenne," Perspectives on Science, 12.2 (2004), 164-190.
} 
and universities. ${ }^{10}$ The set of mathematical practices specific to specialized craftsmen, highlyqualified experts and engineers began to be studied in its own right. ${ }^{11}$

All these reflections may have helped us change our perspectives on the question of mathematization. It seems, however, that they were instead set aside, both because of a general distrust towards sweeping narratives that are always subject to the suspicion that they overlook the unyielding complexity of real history, and because of a shift in our interests. The more obscure and idiosyncratic they are, an alchemist, a patron of the sciences or a lunatic collector is nowadays honored in journals of the history of sciences. As for the general issues involved in the question of mathematization, they are rejected as obsolete, or reserved for specialized journals in the history of mathematics. Consequently, before presenting the essays of this fascicle, I would like to say a few words in favor of a renewed study of the forms of mathematization in the history of the early sciences.

In general, the term "mathematization" refers to the application of concepts, procedures and methods developed in mathematics to the objects of other disciplines or at least of other fields of knowledge. A definition of this kind seems to assume that there is an agreement, first, on what is mathematics, second, on the profits that various disciplines can make out of its application and, third, on the relevance of the very notion of application. But there are many good reasons to think that such an agreement might be difficult to achieve.

There was never a working definition of mathematics in general; even at the time when the traditional definition of mathematics as the "science of quantities" or "magnitudes in general" emerged and was commonly accepted, there were different conceptions of quantities, and consequently different ways of conceiving of the unity of mathematics. ${ }^{12}$ Now, if the second-order question of how to define mathematics was ever raised, it is because it is a

For communication of mathematics, see Jeanne Peiffer, "Faire des mathématiques par lettres," Revue d'histoire des mathématiques, 4 (1998), 143-157; ead., "Communicating Mathematics in the Late $17^{\text {th }}$ century. The Florentine Cupola," in The Circulation of News and Knowledge in Intersecting Networks, ed. Sven Dupré and Sachiko Kusukawa (Oxford, 2008), 92-119; Catherine Goldstein, "L’arithmétique de Fermat dans le contexte de la correspondance de Mersenne : une approche micro-sociale," Annales de la Faculté des sciences de Toulouse, 18 (2009), 25-57. For teaching of mathematics, see Moredechai Feingold, The Mathematicians' Apprenticeship: Science, Universities and Society in England (1561-1640) (Cambridge, 1984); Antonella Romano, La Contre-réforme mathématique : constitution et diffusion d'une culture mathématique jésuite à la renaissance (1540-1640) (Rome, 1999).

11 For the use of mathematics by engineers, see Hélène Vérin, La gloire des ingénieurs : l'intelligence technique du XVI $I^{e}$ au XVIII siècle (Paris, 1993), 167-187, 281-293, passim. On the rationalization of technical practices in general, see Pascal Dubourg Glatigny and Hélène Vérin (eds.), Réduire en art. La technologie de la Renaissance aux Lumières (Paris, 2008). See moreover the references given below, footnote 21.

12 This is shown in relationship with the Aristotelian prohibition rule on kind-crossing by Paola Cantu, "Aristotle's prohibition rule on kind-crossing and the definition of mathematics as a science of quantities," Synthese, 174 (2010), 225-235. 
fundamentally complex field, that included various domains from its very beginning and that kept developing new domains throughout history. ${ }^{13}$ And of course, confining ourselves to pure mathematics to begin with, it underwent many changes between the $14^{\text {th }}$ and the $17^{\text {th }}$ centuries. The reappropriation of ancient texts was crucial in the Renaissance. The point was to reconstruct the methods and the results that Ancient mathematicians, such as Archimedes, Apollonius or Diophantus, had supposedly discovered. In the $17^{\text {th }}$ century, new objects were examined (for example, new curves like the cycloïde or the catenary); ancient problems were solved through new methods (here one can think to Cavalieri's geometry of indivisibles or to the Cartesian algebraization of geometry); new methodological demands were formulated (the exclusion of mechanical curves from Descartes' geometry or the reluctance expressed in geometry with regards to proofs by superposition or proofs by contradiction); and, last, with the emergence of calculus and of infinite series, new domains began to be explored. ${ }^{14}$ In these circumstances, it seems inevitable to admit that we should neither look for a definition of mathematics in general, nor think of mathematics as a unified field ok knowledge, but, rather, submit to an historically situated and empirical determination of mathematics: what should be called "mathematics" is the activities of those who called themselves or were called by others "mathematicians". As tautological and circular as it may appear, such a determination is not without consequence on how we should conceive of mathematization.

Still confining ourselves to pure mathematics, if mathematics itself is diverse, it comes as no surprise that it gives rise to different kinds of mathematization, each of them bringing its own benefits. Arithmetic, in as far as it is the practice of numbers, generates a first form of mathematization: what we call "quantification" consists in capturing in numerical form certain aspects of material things. Such a capture requires indeed measurements, concrete apparatus and a growing concern for precise and standardized data, but also graphical techniques to present numerical results and intellectual techniques of approximation and averaging. Of course, quantification may be only peripherically related to the disinterested search of laws in natural philosophy: the alledged benefits of quantification are sometimes practical. As for geometry, it is implied not only in the highly codified practices of demonstration that involve lettered diagrams and ritual formulas, but more generally in the

Even though it concerns Antiquity, I find Serafina Cuomo, Ancient Mathematics (London, New York, 2001) very helpful here.

14 Besides the works mentioned footnotes 8, 24 and 29, see Niccolò Guicciardini, The Development of Newtonian Calculus in Britain (Cambridge, 1989); Paolo Mancosu, Philosophy of Mathematics and Mathematical Practice in the Seventeenth Century (New York, Oxford, 1996). 
pre-mathematical practices of spatial representation that appear in treatises theorizing procedures of surveying, the art of cartography, the use of linear perspective in painting, etc. Hence, "geometrization" has a wide range of meanings, but its specific benefits are in general related to those of spatial visualization. If arithmetic and geometry were pregnant in the early sciences, the new symbolic algebra raises a distinct hope. Insofar as it is a blind and procedural manipulation of signs, it was seen as leading to a universal science that would be applicable to anything without particular consideration. Now, this diversity does not come only from the diversity of mathematical fields: mathematical practices themselves have different facets, and each of these different facets may suggest a certain kind of mathematization. For example, the apodictic way in which mathematics conducts its demonstrations and the necessity it confers to its results exerted an enduring fascination. Superficial as it may be with respect of the actual practices of mathematicians, the ensuing demand for more geometrico presentations implies significant constraints. We can speak of "axiomatisation" in this case, even when the identification of a coherent set of axioms and definitions, from which to derive the other propositions, was not completely operative.

Calling "mathematics" the activities of those who called themselves, or were called by others, "mathematicians" has a second consequence: we should stop thinking of mathematization as an application of pure mathematics. The $19^{\text {th }}$ century notion of application is obviously not historically appropriated. In the early sciences, what was contrasted was not "pure" versus "applied" mathematics, but "pure or abstract" versus "mixed" mathematics, and "speculative or theoretical" versus "practical" mathematics. The problem is not just a question of words. The contemporary notion of application and the correlative opposition between "pure mathematics" and "applied mathematics" are based on the idea that there are certain mathematical procedures that do not need to be transformed to give satisfying explanations of the phenomena under consideration. ${ }^{15}$ This idea is certainly adapted to certain cases: even if a ray of light is not a straight line, the geometry of the straight line can be applied to the ray of light; the theory of proportions was indeed applied to the analysis of motion,. But early modern mechanics is a canonical example in that the analysis of certain phenomena may require not only a transformation of the existing

\footnotetext{
15 These characteristics of the notion of application were first identified by Louis Althusser, Philosophie et philosophie spontanée des savants (Paris, 1967), 31-32, who, moreover, claimed that the relation of mathematics to physics, is not a relation of "application," but a relation of "constitution," in as far as mathematical language "constitute" the objects of physical mathematics. In French scholarship at least, Althusser's point was popularized by Jean-Marc Lévy-Leblond, "Physique et mathématique," in Penser les mathématiques (Paris, 1982), 195-210. There has been consequently a tendency to priviledge "true mathematisation" over "simple application," but the more I think about it, the more I think that the conceptual distinction is justified, but that the depreciation of application is an historical dead-end.
} 
mathematical tools, but, ultimately, the constitution of new mathematical objects. ${ }^{16}$ Moreover, the notion of application does not seem appropriate for arts that were qualified as "practical mathematics" in the $16^{\text {th }}$ and $17^{\text {th }}$ centuries: surveying, building fortifications and canals, navigation, architecture, book-keeping, inventing machines for war and/or peace, drawing perspective, etc. Some kind of mathematics was indeed mobilized in these practices, but as the mathematics of the time is not able to explain them satisfactorily, the contemporary notion of application does not help to see what is at stake in them. We must, rather, understand them as a pre-mathematical material that formal mathematics theorizes. The pre-mathematical (for example, land-surveying) is historically prior to the mathematical (in this case geometry); the pre-mathematical material comes from a human symbolical practice (triangles are not found in nature, but constructed according to definite procedures by humans that have social needs and symbolical means). Mathematics consists of inserting this pre-mathematical material into a second-order discourse. ${ }^{17}$

These remarks may converge in the conclusion that the grand narrative about mathematization of nature has to be replaced with the dense spectrum of various mathematical practices. And, indeed, deserting the idealities that Husserl and Koyré waved at for real practices like manipulating numbers, extracting roots, representing perspective in pictures, compounding proportions, arranging numbers in tables, following rules and algorithmic procedures, knitting propositions together, visualizing magnitudes in geometric diagrams, solving problems, measuring fields with specific instruments, drawing curves, making deductions and plotting the routes of ships, was a significant and much needed change of scenery. ${ }^{18}$ However, the term "practice" seems today to be so indefinitely extendable, that it is not easy, beyond the slogan, to know exactly what it means. This ambiguity has not been without intellectual benefits, since it helped us to come out of idealism, but we must now ask ourselves what speaking of practices commit us to.

It seems to me that the term "practices" has at least three accepted usages, that are not mutually exclusive, but that should help us in understanding where we stand. First, speaking of mathematical practices may imply that a descriptive and historical point of view is adopted, rather than a normative and philosophical perspective; in that sense, the term

\footnotetext{
16 See the references given above, footnotes 7 and 8.

17 Paul Raymond, Le passage au matérialisme (Paris, 1973), 329-331. Enrico Giusti, Ipotesi sulla natura degli oggetti matematici (Turin, 1999) helps clarifying this hypothesis and showing that it may be adapted to more complicated and better documented cases than the hypothetical emergence of geometry from landsurveying.

${ }_{18} \quad$ Note in this respect that neither Husserl nor Koyré cared for such practices, not even for the practices of pure mathematics.
} 
"practice" refers simply to "mathematics as it is done, not as it should be done according to some preconceived philosophical viewpoint". ${ }^{19}$ As the previous pages suggest, adopting such a point of view ineluctably leads one to take into account a swarm of small problems and local methods, which generate an image of mathematics quite different from the still received view, according to which it is expected to grow continuously and uniformly from a limited set of definitions and axioms. Second, practices may refer to the non-verbal commitments shared by mathematicians that help them defining a scientific style and constituting an intellectual community; practices in this sense are opposed to explicit beliefs and assumed to be invisible to the mathematicians themselves. The book I am here thinking of - that may be idiosyncratic in this respect — being concerned with cognitive practices, such practices may be interpreted as logical conditions for the possibility of the emergence of the Greek deductive style. ${ }^{20}$ Third, in accordance with the actors' categories, mathematical practices can be identified with practical mathematics, as contrasted with pure mathematics and which refers to the real world, with its economic interests, practical concerns, material instrumentation, local settings and complex social networks. Even Kuhn's rehabilitation of the Baconian sciences relied on a clear-cut separation between the mathematical tradition and the experimental tradition, and also on a valorization of the abstract realm of pure ideas to the detriment of the concrete world of allegedly confused practices. The historiographical function of such mathematical practices at this point is neither more nor less than bridging the gap between intellectual and social history. ${ }^{21}$

The essays of this fascicle are by and large concerned with practices in the first sense: their point is neither to identify the formal conditions of possibility of deduction, nor to follow the practical engagements of scientists in the real world out there, but to capture some aspects of mathematics as it was pursued in various fields of knowledge. To avoid ambiguity, the title of the fascicle is consequently Forms of Mathematization. But, of course, forms are not Platonic ideas here: mathematical objects are not given once and for all in an ideal world, they are historically constructed. The notions of operative knowledge and of knowing by doing should be taken seriously when we deal with pure mathematics, because in order to know-that (this is true), mathematicians begin by knowing-how (to draw a diagram, to find

\footnotetext{
19 Mancosu, Philosophy of mathematics, 4.

20 Reviel Netz, The Shaping of Deduction in Greek mathematics : a Study in Cognitive History (Cambridge, 1999), 3-7.

21 Jim Bennett, "The Challenge of Practical Mathematics," in Science, Culture and Popular Belief in Renaissance Europe, ed. Stephen Pumfrey and al. (Manchester, 1991), 176-190; id., "Practical Geometry and Operative Knowledge," Configurations 6.2 (1998), 195-222. The blurring of Kuhn's two traditions is also manifest in the ambiguous nature of the "objects" studied by Meli, Thinking with Objects, see in particular 1-6, 310-316.
} 
the solution of an equation, to construct a curve, to make an operation, etc. $)^{22}$

The three first essays of this fascicle, by Sylla, Boulier and Palmerino, are devoted to an exemplary question as far as mathematization of nature is concerned; namely, the question of mathematization of motion. However, these essays do not aim at identifying the roads that led to the discovery of one canonical law of motion or another. Rather, they bring to the fore certain specific forms of mathematization that were associated with the mathematization of motion: deductive reasonings on motions, alternative mathematical methods for the analysis of motion and geometrical diagrams representing motions.

Sylla focuses on the community of the $14^{\text {th }}$ century Oxford Calculators (William Heytesbury, John Dumbleton and Richard Swineshead). The first challenge of her paper is to enlighten the kind of mathematization involved in the formulation of the middle-degree theorem without applying the prism of Oresme - who introduced the first graphic representation of this theorem — nor seeing this theorem through Galilean glasses. ${ }^{23}$ Recalling that the incentive for this theorem was Bradwardine's De proportionibus velocitatum in motibus (1328), and that it was formulated in the context of the undergraduate exercises called sophismata, she explains that the key-concept of latitude of velocity could not have been formulated if velocities would have continued to be conceived as forms naturally inhering to bodies, rather than as homogeneous and additive entities. Moreover, the examples of reasoning that Oxford Calculators developed in this context illustrate the possibility of a science of motion organized as the deductive system of geometry, since consequences are inferred from the initial definitions of uniform and difform motions. Sylla

22 Here I can not help refering to George-Théodule Guilbaud, Mathématique sociale, entretien avec E. Coumet, P. de Mendez et P. Rosenstiehl, Savoir et Mémoire, 4 (Paris, 1993), 3 : “[...] la mathématique, c’est un exercice : on ne "sait" pas des mathématiques, on en "fait"! [...] S'il n'y avait pas de mathématiciens, est-ce qu'il y aurait, dans l'histoire de l'humanité, de la mathématique ? Voilà le problème, c'est l'absence d'objet véritable, d'où la nécessité de les fabriquer et de les refabriquer [...]. [O]n n'applique pas les mathématiques à quelque chose. Disons plutôt qu'il y a un réel, un donné, et si j'entre dans cet univers-là avec un esprit mathématisant, je vois des choses que peut-être d'autres n'auraient pas vues".

23 This essay follows on previous papers written by Sylla. Among the more recent ones, see "Mathematical Physics and Imagination in the Work of the Oxford Calculators: Roger Swineshead's On Natural Motions," in Mathematics and Its Application to Science and Natural Philosophy in the Middle Ages, ed. Edward Grant and John Murdoch (Cambridge, 1987), 69-101; "The Oxford Calculators and Mathematical Physics: John Dumbleton's Summa Logicae et Philosophiae Naturalis, Parts II and III," in Physics, Cosmology and Astronomy, 1300-1700: Tension and Accommodation, ed. Sabetai Unguru (Dordrecht, 1991), 129-61; "Thomas Bradwardine's De continuo and the Structure of Fourteenth-Century Learning," in Texts and Contexts in Ancient and Medieval Science. Studies on the Occasion of John E. Murdoch's Seventieth Birthday, ed. Edith Sylla and Michael McVaugh (Leiden, 1997); "The Origin and Fate of Thomas Bradwardine's De proportionibus velocitatum in motibus in Relation to the History of Mathematics," in Mechanics and Natural Philosophy, 67119; "The Academic Context of Walter Burley's Tractatus Primus," to appear in the Proceedings of the XII International Congress of Medieval Philosophy, Palermo 2007. 
ends up with the question of how one should explain the Calculators' move: according to her, their philosophical commitment to the kind of ontological minimalism promoted by Ockham would have been decisive. Ockham's ontological nominalism would have allowed them to study a concept, like the concept of latitude of velocity, that does not refer directly to anything real in the world. This essay indirectly points to an interesting question: to what extent the concept of latitude of velocity or an inference such as "if the motion is uniformly difform, then the distances it will traverse in successive units of time will be as the odd numbers" can be qualified as mathematical, rather than as logical? Mathematical objects are indeed complex objects; ones that articulate rules of logical inference, constraints of manipulation of formalisms, graphic notations, symbolic practices, techniques for solving problems, etc. From a broader perspective, one could argue that the Calculators explored one of the many facets that the Galilean science of motion happens to articulate together.

The process of ontological disengagement that, according to Sylla, Oxford's Calculators promoted, intervenes as well in Boulier's essay. ${ }^{24}$ Boulier offers a synthetic account of a wellknown paradox: while Galileo believed that the continuum is actually composed of indivisibles, he rejected, officially at least, Cavalieri's method of the indivisibles. Boulier starts from the opposition between Galileo's and Cavalieri's views concerning the indivisibles. For Galileo, indivisibles are physical realities, the properties of which can be studied (even if they lead to paradoxes); while for Cavalieri, indivisibles are embodied in a method relying on the equivalence between sets of infinite indivisibles and finite magnitudes. To make this contrast more precise, Boulier proceeds in three steps. First, he studies the paradoxes concerning indivisibles presented in the First Day of the Discorsi; second, he examines the Cavalerian method of indivisibles, which remains neutral with regards to their existence as ultimate components of a plane figure; last, he argues that, in the Third Day of the Discorsi, Galileo does not rely on the Cavalerian method because he would have remained attached to the "ideal of intelligibility" expressed in the theory of proportions. Perhaps the theory of proportions should not be seen so much as an abstract ideal of intelligibility, than as a set of rules and general procedures that constrains mathematical reasoning and help it become organized in a coherent whole. On the other hand, in the

\footnotetext{
24 Preliminary studies to Boulier's essay are Enrico Giusti, Bonaventura Cavalieri and the Theory of Indivisibles (Rome, 1980); Kirsti Andersen, "Cavalieri's Method of Indivisibles," Archive for History of Exact Sciences, 31 (1985), 291-367; Giusti, "Galilei e le leggi”; Michel Blay and Egidio Festa, "Mouvement, continu et composition des vitesses au XVII ${ }^{\mathrm{e}}$ siècle," Archives internationales d'histoire des sciences, 48 (1998), 65-118; Carla Rita Palmerino, "Una nuova scienza della materia per la scienza nova del moto. La discussione dei paradossi dell'infinito nella prima giornata dei Discorsi galileiani," in Atomismo e continuo nel XVII secolo. Atti del Convegno Internazionale (Napoli, 28-30 aprile 1997), ed. Egidio Festa and Romano Gatto (Naples, 2000), 275-319.
} 
method of indivisibles, in as far as there is no procedure for identifying "all the lines" of a plane figure, they are to be seen on the diagram. If this is true, the reason why Galileo does not rely on the method of indivisibles would be that this method was not associated with a procedure sufficiently autonomous from diagrams.

However, Galileo's geometrization of motion relies on geometrical diagrams, and their function comes under scrutiny in Palmerino's essay. It has been conclusively argued that geometrical diagrams, being associated to the specific form of mathematization that geometrization is, were doomed to disappear once the abstract procedures of the infinitesimal and differential calculus were applied to the analysis of motion (by the end of the $17^{\text {th }}$ century, the mathematics of motion does not proceed by drawing pictures, but by writing equations). ${ }^{25}$ However, Palmerino focuses on precisely the period when diagrams were crucial to the mathematization of motion in order to define their exact function in an historiographical context distinguished by a renewed interest in diagrams ${ }^{26}$. According to her, the unpublished diagrams of acceleration that Galileo drew helped him understanding that the degree of velocity in accelerated motion is proportional to the time elapsed and not to the space traversed. In fact, in one of Galileo's diagram, the space traversed by the falling body is represented at the same time by a line and an area, while in another, the same segment represents at the same time the space traversed and the time elapsed during the fall. Hence, Palmerino's argument is that diagrams were not only material supports of proofs as it is the case in general in geometry, but heuristic tools for the science of nature. According to her, a tacit assumption of Galileo's would be that any law of nature could be associated to a coherent geometrical representation. Moreover, she suggests that the reason why Cavalieri and Gassendi, although endorsing Galileo's law of free fall, substituted his diagram of acceleration with alternative diagrams may have been that a vertical line figuring in the Galilean diagram could have been mistaken for the distance traversed during the fall.

Michael Mahoney, "Diagrams and Dynamics: Mathematical Perspectives on Edgerton's Thesis," in Science and the Arts, ed. J. W. Shirley and F. D. Hoeniger (Cranbury, NJ, 1985), 198-220; id., "Drawing Mechanics," in Picturing Machines 1400-1700, ed. Wolfgang Lefèvre (Cambridge, 2004), 281-306. The degeometrization is obviously not specific to mechanics, but should be rather seen as the disentanglement of analysis itself from its first geometrical context.

$26 \quad$ See for example Judith V. Field, "Renaissance Mathematics: Diagrams for Geometry, Astronomy and Music," Interdisciplinary Science Reviews, 29 (2004): 259-77; Sven Dupré, "Vizualisation in Renaissance Optics: the Function of Geometrical Diagrams and Pictures in the Transmission of Practical Knowledge," in Transmitting Knowledge: Words, Images, and Instruments in Early Modern Europe, ed. Sachiko Kusukawa and Ian Maclean (Oxford, 2006), 11-39. On the emergence of the lettered diagram in Greek geometry, see Netz, The Shaping of Deduction, 13-88, and for a cognitive perspective on diagrams, see, among many studies, Jill $\mathrm{H}$. Larkin and Herbert A. Simon, "Why a Diagram is (Sometimes) Worth Ten Thousand Words," Cognitive Science, 11 (1987), 65-99. 
If a moral must be drawn from these first three essays, then surely, it is that the classical mathematization of motion evolves from the interplay of different forms of mathematization, "forms" referring in the present cases to the reasoning of the Calculators, the method of Cavalieri and the diagrams of Galileo. The second group of essays, by Husson, Raynaud and Andrault, deals with case studies devoted to the so-called "application" of mathematics to various practices - from medieval music to Early Modern anatomy, passing through Renaissance perspective. The common denominator of these three essays is that they examine how mathematics is introduced into practices that may appear more distant from mathematics than mechanics is; namely, music, perspective and anatomy. They differ, however, since they do not expose the introduction of mathematics to the same light: Husson studies the theoretical justifications that are given of mathematization, Raynaud analyses its demonstrative effectiveness; Andrault details different aspects of the more geometrico.

Husson focuses on the uses of mathematics in the early $14^{\text {th }}$ century theory of music; a challenging period since it witnessed the development of polyphonic practices and the transformation of music from a discipline of the quadrivium into a scientia media. ${ }^{27}$ In his introduction, Husson distinguishes two types of mathematization, depending on whether the "descriptive function of mathematics is extended (this is the case when mathematics is applied to new objects) or the "argumentative function" of mathematics is extended (this is the case when a new argumentative role is ascribed to mathematics). An example of the first type of mathematization is given by Jehan des Murs, Master of Arts at the University of Paris, who used integers to measure not only the pitch, as was usual in his time, but also the duration of a musical sound. Husson shows that des Murs' justification relies on a parallel between sound and motion, which allows one to resort to arguments developed in Aristotle's Physics. An example of the second type of mathematization is given by Johannes Boen, a Dutch priest who assured the formation of cantors: he used mathematical reasonings to argue that the construction of half-tone is possible, which would not be the case if music was strictly subordinated to arithmetic. Mathematization of the musical practices thus relies on the interplay between various discourses, from Aristotle's Physics to Boethius' De institutione musica, passing by considerations on the perfection of the number three.

While Husson examines the justifications given in favor of the introduction of mathematical elements in a practice, Raynaud shows that a practice can be retroactively

\footnotetext{
27 Classical studies concerning music in the $14^{\text {th }}$ century are Dorit E. Tanay, Music in the Age of Ockham: the Interrelations between Music, Mathematics, and Philosophy in the 14th Century (Berkeley, 1989); Frank Hentschel, Sinnlichkeit und Vernunft in der mittelalterlichen Musiktheorie (Stuttgart, 2000); Gilles Rico, Music in the Arts Faculty of Paris in the Thirteenth and Early Fourteenth Centuries, D. Phil. Thesis (Oxford, 2005).
} 
explained by hypotheses leading to mathematical reasoning. The history of perspective during the Renaissance exhibits indeed what Raynaud felicitously calls a case of "retroactive mathematization". In order to defend a standardized system of perspective against those who rejected it, for example, in the name of painters' rules of thumb, the mathematical hypotheses that could retroactively explain the choice of this standardized system were sought after. The identification of these hypotheses by Piero della Francesca, Giacomo Barozzi da Vignola, Pietro Cataneo or Egnatio Danti, to name just a few, amounted to an arbitrary restriction on the field of vision to a $60^{\circ}$ angle, to the false hypothesis that the eye does not move, to the tentative eviction of the curvilinear perspective and to the erroneous assumption that the natural vision is monocular. As arbitrary or even false as they were from a physiological perspective, these hypotheses were, however, chosen because they could serve as starting points of mathematical proofs and allow for a standardization of the practices, in particular in the context of teaching. Hence, the mathematization of perspective implied neither quantification nor axiomatisation, but, rather, relied on the demonstrative power of mathematics and on its potential for standardization and simplification. In his conclusion, Raynaud insists that Renaissance theoreticians of perspective had a dual competence (as mathematicians and as painters, engineers or architects) and that geometrical optics played a mediatory function between geometry and perspective.

In contrast to Raynaud, Andrault focuses on one single book; namely, Niels Steno's Elementorum Myologiae Specimen (1667), which is regularly taken as an exemplary case of mathematization since it pretends to geometrize the muscles and their movement of contraction. However, argues Andrault, the more geometrico order asserted by Steno has rarely been studied for its own sake. ${ }^{28}$ She argues that Steno's aim was neither to offer an ontological reduction of the muscles to mathematical figures nor to give a mathematical explanation of the functioning of the muscles, but, rather, to give a simplified description of the muscular fibers as parallelepipeds and to suggest that their contraction may possibly be explained without making the usual assumption that they swell because of an augmentation of their volume due to the influx of animal spirits. In this case, mathematization is primarily linked to a process of abstraction that amounts to representing the muscular fibers as parallelepipeds. This abstract representation allows a comparison of explanations that does Steno on muscles, (Philadelphie, 1994); id., "Nicolas Steno's New Myology," Nuncius, 23 (2008), 37-64; Domenico Bertoloni Meli, "The Collaboration between Anatomists and Mathematicians in the mid-Seventeenth Century with a Study of Images as Experiments and Galileo's Role in Steno's Myology," Early Science and Medicine, 13 (2008), 663-709. 
not prejudge which of these explanations happens to be empirically true. Finally, Andrault insists that Steno's Specimen, in contrast to, for example, Alfonso Borelli's De motu animalium but also contrary to Steno's own anatomical writings, follows a true synthetic order, where only the hypotheses necessary to the subsequent demonstrations are displayed. Hence, Steno offers a rather pure example of the application of elementar geometry to another field of knowledge; as he wrote at the end of the $17^{\text {th }}$ century, he did not feel the need of providing long justifications for what he was doing.

The question of mathematization can finally be, so to speak, turned on itself, i.e., related to pure mathematics itself. In the essay that concludes this fascicle, Maronne shows that, given the variety of mathematics, one can speak without pun of a mathematization of mathematics: applying mathematics to a non-mathematical discipline displays only a difference of degree with applying a part of mathematics to another part of mathematics. As has been pointed out from the start, mathematics provides symbolic tools that are not designed to perform any specific task. Given this, it's only natural that the Cartesian algebraization of geometrical problems didn't turn out to be a transposition that carried no cost. ${ }^{29}$ The cost in this case, which, as Maronne recalls, was totally assumed by Descartes himself, is that it can be difficult to give the actual construction of the geometric objects that correspond to the algebraic solution of the problem proposed. Thus, the Cartesian algebraization of geometry created a new epistemological situation: in certain cases, there might be a discrepancy between the easy algebraic solution of an equation and the difficult geometrical construction of this solution. Referring to classical problems like Apollonius' problem of the three circles or Pappus' problem, but also to the correspondence between Blaise Pascal and René-François de Sluse during the year 1657, Maronne consequently examines the different attitudes mathematicians adopted towards the geometrical construction of algebraic solutions. Descartes thought that the game is not worth the candle. Pascal had proposed a wholly geometrical solution of Pappus's problem that implies an actual construction of all possible cases. Sluse, at last,embodied an intermediary position: on the one hand, he defended Descartes' analysis, while on the other, he was inclined to think that a geometrical construction of the algebraic solution of problem is necessary, even if he did not always provide it.

29 The background to Maronne's essay is Henk Bos, Redefining Geometrical Exactness. Descartes' Transformation of the Early Modern Concept of Construction (New York, 2001). 